\title{
Chinese Hypertension Guidelines
}

\author{
Ji-Guang Wang
}

Centre for Epidemiological Studies and Clinical Trials, Shanghai Key Laboratory of Hypertension, The Shanghai Institute of Hypertension, Ruijin Hospital, Shanghai Jiaotong University School of Medicine, Shanghai, China

\section{Key Words}

Chinese hypertension guideline $\cdot$ Prevalence $\cdot$ Treatment $\cdot$ Control rates $\cdot$ Blood pressure control · Antihypertensive drugs

\begin{abstract}
According to the 4th National Nutrition and Health Survey in 2002, the prevalence of hypertension in China was $18.8 \%$. Although there are no recent updated nationwide data, it is believed that the prevalence of hypertension has increased substantially in the past decade up to more than 200 million hypertensive patients in the populous country of China. To fight against the growing risk of hypertension, three Chinese hypertension guidelines were compiled in the past two decades, in 1999, 2005, and 2011. The current guidance document for the management of hypertension was named '2010 Chinese hypertension guideline', but it was actually published in 2011. In this guideline, all five classes of antihypertensive drugs were recommended as possible initial and maintenance therapy. The goal of treatment was a systolic/diastolic blood pressure below 140/90 $\mathrm{mm} \mathrm{Hg}$ in general, $130 / 80 \mathrm{~mm} \mathrm{Hg}$ in various groups of high-risk patients, and $150 / 90 \mathrm{~mm} \mathrm{Hg}$ in the elderly ( $\geq 65$ years). With the recent publication of several national and international hypertension guidelines, the Chinese guideline is now under discussion for updating.

(C) 2015 S. Karger AG, Basel
\end{abstract}

\section{Introduction}

From 2013 to 2014, several national [1, 2] and international [3, 4] hypertension guidelines were published. Although some of those guidelines did not change very much concerning the therapeutic management of hypertension [1,3], some others did have significant changes with respect to the target blood pressure of treatment in general and in various subgroups of hypertensive patients [2,4]. The current Chinese hypertension guideline was published in 
Table 1. Prevalence, awareness, treatment, and control rates of hypertension in two recent nationwide blood pressure surveys in China [2, 3]

\begin{tabular}{llllllll}
\hline & Subjects, $\mathrm{n}$ & $\begin{array}{l}\text { Prevalence, } \\
\%\end{array}$ & $\begin{array}{l}\text { Awareness, } \\
\%\end{array}$ & $\begin{array}{l}\text { Treatment, } \\
\%\end{array}$ & $\begin{array}{l}\text { Aware and } \\
\text { treated, } \%\end{array}$ & $\begin{array}{l}\text { Control, Treated and } \\
\%\end{array}$ & $\begin{array}{l}\text { Trentrolled, } \% \\
\text { contr. }\end{array}$ \\
\hline $1991(\geq 15$ years) & 950,356 & 11.3 & 26.6 & 12.1 & 45.5 & 2.8 & 23.1 \\
$2002(\geq 18$ years) & 141,892 & 18.8 & 30.2 & 24.7 & 81.8 & 6.1 & 25.0 \\
$2002(\geq 60$ years) & not reported & 49.1 & 37.6 & 36.2 & 96.3 & 7.6 & 24.1 \\
\hline
\end{tabular}

2011 [5] and is now under discussion for updating. Although the Chinese Hypertension League has not officially declared start-up for updating the Chinese hypertension guideline, it is very likely that a committee will soon form and convene in late 2015 or early 2016.

China is a fast-growing and -ageing nation with approximately 200 million hypertensive patients. It would be useful to scrutinize what kind of guideline the country will need to tackle the huge current and emerging cardiovascular risk of hypertension. The present review describes the challenges in the management of hypertension in China and the history of the Chinese hypertension guidelines and attempts to provide some insights into the current and future guidance documents for the management of hypertension in China.

\section{Challenges in the Management of Hypertension in China}

In 1991 and 2002, two nationwide blood pressure surveys were conducted in China (table 1) [6, 7]. In 1991, about 1 million people of at least 15 years were surveyed [6]: 11.3\% had a blood pressure of at least $140 \mathrm{~mm} \mathrm{Hg}$ systolic or $90 \mathrm{~mm} \mathrm{Hg}$ diastolic or had used antihypertensive medication. The awareness, treatment, and control rates were 26.6, 12.1, and $2.8 \%$, respectively. Of those who were aware of hypertension, the treatment rate was $45.5 \%$. Of those who were treated, the control rate was $23.1 \%$. In the 4 th National Nutrition and Health Survey in 2002, blood pressure was measured [7]. In this survey of 141,892 subjects, the prevalence, treatment, and control rates of hypertension were $18.8,24.7$, and $6.1 \%$, respectively. In comparison with the data in 1991, the treatment rate in hypertensive patients increased to $81.8 \%$. However, the awareness and control rate in treated hypertensive patients remained virtually unaltered. In the elderly of at least 60 years, about half had hypertension, and the control rate was slightly higher than in younger subjects, mainly due to the higher awareness and treatment rate in hypertensive patients [7].

Until recently, there have been no updated nationwide data on the prevalence of hypertension in China. Nonetheless, there were vast amounts of data from single-center regional surveys on hypertension and from multicenter studies on other chronic diseases, such as diabetes mellitus. In a multicenter survey on the prevalence of diabetes mellitus, population samples of at least 20 years of age were randomly selected. The prevalence of hypertension was extraordinarily high, being $30.09 \%$ in men $(n=18,976)$ and $24.79 \%$ in women $(n=$ 28,349 ) [8]. This study might have overestimated the prevalence of hypertension to some extent. However, the prevalence of hypertension on the population level in China might indeed have substantially increased in the past few years, because the net increase in the number of elderly people ( $\geq 60$ years) was more than 10 million each year since 2010 . The number of elderly people in China now amounts to more than 200 million. This increasing trend will continue for the next 20 years and end up with at least 400 million people older than 60 years. Simply for this reason, the number of hypertensive patients will increase 
Wang: Chinese Hypertension Guidelines

rapidly up to several hundred million in the next 20 years, because according to the recent survey, $50 \%$ of people older than 60 years had hypertension [9]. In addition, lifestyle in China changes rapidly and is characterized by a high-salt, high-fat, high-sugar, and high-calorie diet, high anxiety and stress in life and work, and low physical activity. This typical lifestyle will undoubtedly further worsen the situation. Hypertension will inevitably become an even more serious public health problem in the next 1-2 decades for China.

\section{History of the Chinese Hypertension Guidelines}

The first Chinese hypertension guideline was printed in a booklet in 1999 and had never been published anywhere. This guidance document was probably not so sophisticated but nevertheless played a role in improving the management of hypertension at that time in China. As mentioned above, the treatment rate of hypertension increased substantially from $45.5 \%$ in 1991 [6] to $81.8 \%$ in 2012 in patients who were aware of the disease [7]. The improvement to some extent could be attributed to the promotion of the first Chinese hypertension guideline at the beginning of the 21st century.

In 2004, the Chinese Hypertension League formed a guideline committee and, for the first time, published a guidance document for the management of hypertension in a supplemental issue of the Chinese Journal of Hypertension in 2005 [10]. This document was prepared and published right after the first European Society of Hypertension guideline in 2003 [11] and, therefore, was influenced heavily by the European guidance document. For instance, all five classes of antihypertensive drugs, namely calcium channel blockers, angiotensin-converting enzyme inhibitors, angiotensin receptor blockers, thiazide diuretics, and $\beta$-blockers, were recommended as a possible choice for initial and maintenance antihypertensive therapy. This recommendation was distinct from that of the 'Seventh report of the Joint National Committee on Prevention, Detection, Evaluation, and Treatment of High Blood Pressure' (JNC 7), which was also published in 2003 and recommended thiazide diuretics as the only first-line therapy in the absence of compelling indications [12].

\section{Current Chinese Hypertension Guideline}

The current Chinese hypertension guideline was published in 2011 simultaneously in the Chinese Journal of Cardiology [5] and Chinese Journal of Hypertension [13]. This guidance document was named '2010 Chinese hypertension guideline' and was considered as an update of the 2005 guideline. This updated Chinese hypertension guideline was a comprehensive document and dealt with all issues of hypertension including secondary hypertension and various special populations, such as young and old age groups, patients with stroke, coronary heart disease, diabetes mellitus, and chronic kidney disease, etc. For the principles of antihypertensive treatment, the recommendations included low-dose initiation, longacting medication, combination therapy, and individualization. For the choice of antihypertensive drugs, the guideline continued to recommend all five classes of antihypertensive drugs. In the meantime, because the dihydropyridine calcium channel blockers have the best evidence from controlled clinical trials in China [14-17] and are more efficacious in lowering blood pressure in the Chinese population [18], this class of drugs was listed in the first place among the recommended drugs [5, 13].

After the publication of the current Chinese hypertension guideline, the principles of long-acting medication and combination therapy were actively promoted by working on two specific guidance documents in relation to antihypertensive therapy. One was the 'Science 
advisory on the use of morning blood pressure in the management of hypertension' published in 2014 [19]. Short-acting drugs are still widely used in the management of hypertension and might be the reason for the low control rate of hypertension [9], especially when the efficacy is evaluated in the trough hours, usually in the morning. By measuring blood pressure in the morning before drug intake, a patient is more likely to be able to recognize the difference in blood pressure control between short- and long-acting drugs and may therefore change from short- to long-acting antihypertensive drugs. In the past few years, this campaign has led to a substantial increase in the use of long-acting drugs in China.

Another guideline was the 'Chinese expert consensus document on antihypertensive therapy with single-pill combination' published in 2012 [20]. According to a recent survey, although the control rate of hypertension was only $30.6 \%$, the use of combination antihypertensive therapy remained low, being $45.9 \%$ in patients seen in big hospitals of big cities [21]. Single-pill combinations of currently recommended antihypertensive drugs, such as inhibitors of the renin-angiotensin system combined with a calcium channel blocker or a thiazide diuretic, became available in China in the past decade. Although there is growing evidence in the Chinese population that the use of single-pill combination antihypertensive drugs may significantly improve efficacy and tolerability $[22,23]$, these drugs are still insufficiently used in treating hypertension. Thiazide diuretic as a component of these single-pill combination drugs could be a reason. A single-pill combination of an inhibitor of the renin-angiotensin system with a calcium channel blocker might change the situation in the future.

Low-dose initiation is actually a tradition in the use of antihypertensive drugs in China. This style may have led to the underuse of antihypertensive drugs and, hence, to the low control rate of hypertension [9]. The current European Society of Hypertension [3] and the American guidelines [2] recommend the use of the full dose or maximum dose of antihypertensive drugs regardless of mono- or combination therapy. This change might help in the adequate dosing of antihypertensive drugs.

Individualized use of medication relies on the expertise of physicians. Every physician can do it, but does it differently. For now, what we can and should do is to adhere to the principles of indication and contraindication. Probably, with the emerging molecular and other biological techniques, individualized or personalized therapy can be achieved in the future.

In the current Chinese hypertension guideline $[5,13]$, the goal of antihypertensive treatment was defined according to age and associated diseases, such as diabetes mellitus, chronic kidney disease, coronary heart disease, etc. In general, the goal was a systolic/diastolic blood pressure below 140/90 $\mathrm{mm} \mathrm{Hg}$, including for those with a history of stroke. However, in patients with the abovementioned diseases, the goal was below 130/80 mm Hg. In patients of 65 years or older, the goal was below 150/90 mm Hg.

\section{Perspectives on Future Chinese Hypertension Guidelines}

We do not know what the next Chinese hypertension guidelines will look like. However, we can always state what we would like them to be. We apparently need novel strategies in the fight against hypertension. Otherwise, we may fight a losing battle. A strategic approach is to substantially simplify the guidelines, as it has recently happened for the JNC 8 guidance document [2]. Such an approach has also been recently proposed and discussed in China (fig. 1) [24]. Every 'normotensive' person should measure their blood pressure at home regularly at least once a year. Hypertension can then be diagnosed within a year of onset and treated timely and efficiently. Uncontrolled patients will be evaluated by ambulatory blood pressure monitoring for the identification of those with truly uncontrolled hypertension [25] and by advanced imaging and nonimaging techniques for the detection of target organ damage and arterial 


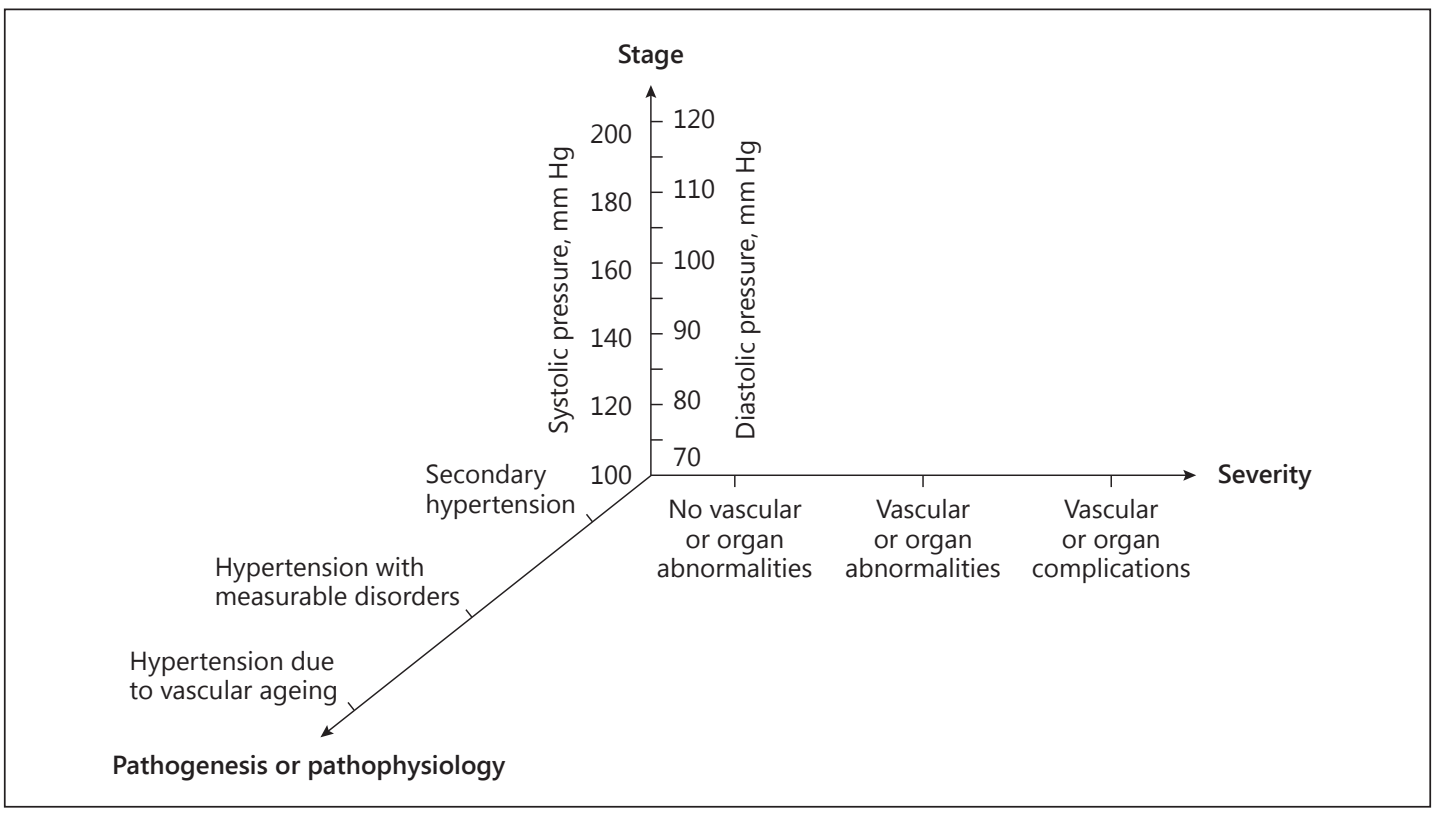

Fig. 1. Rationale for classifications according to blood pressure level, disease severity, and pathogenesis or pathophysiology in the management of hypertension. Treating blood pressure to the target level should be the focus of antihypertensive therapy (vertical axis). In truly uncontrolled hypertension, disease severity should be evaluated by measuring function and structure of the vascular system and the target organs, and then specific interventions and treatment can be considered (horizontal axis). Only those patients with characteristics suggestive of secondary hypertension or specific pathogenesis or pathophysiology should undergo screening for secondary causes of hypertension (lateral axis).

lesions. These evaluations will provide evidence of compelling indications for specific interventions and treatment. In this process of evaluation, some patients might show characteristics suggestive of secondary hypertension and, hence, may need to undergo an on-target screening for secondary causes of hypertension. The proportion of secondary hypertension may not be large. However, with the increasing number of hypertensive patients, the absolute number of patients with secondary hypertension can still be huge in a country like China.

Eastern Asians share similar characteristics of hypertension [18] and should jointly fight against the disease in the region $[1,5,26]$. There are some discussions on a possible common hypertension guideline in Asia. The current initiative of the Pulse journal could be considered as a starting point of this process.

\section{Acknowledgement}

The authors were financially supported by grants from the National Natural Science Foundation of China (grants 81170245, 81270373, and 81470533) and the Ministry of Science and Technology [2013CB530700 and a grant for China-European Union collaborations (1012)], Beijing China, the Shanghai Commission of Science and Technology (11QH1402000 and 15XD1503200), and the Shanghai Bureau of Health (XBR2011004).

\section{Disclosure Statement}

Dr. Wang receives consulting and lecture fees from Astra-Zeneca, Boehringer Ingelheim, MSD, Novartis, Pfizer, Daiichi-Sankyo, Sanofi, and Servier. 
Wang: Chinese Hypertension Guidelines

\section{References}

1 Shimamoto K, Ando K, Fujita T, Hasebe N, Higaki J, Horiuchi M, Imai Y, Imaizumi T, Ishimitsu T, Ito M, Ito S, Itoh H, Iwao H, Kai H, Kario K, Kashihara N, Kawano Y, Kim-Mitsuyama S, Kimura G, Kohara K, Komuro I, Kumagai H, Matsuura H, Miura K, Morishita R, Naruse M, Node K, Ohya Y, Rakugi H, Saito I, Saitoh S, Shimada K, Shimosawa T, Suzuki H, Tamura K, Tanahashi N, Tsuchihashi T, Uchiyama M, Ueda S, Umemura S; Japanese Society of Hypertension Committee for Guidelines for the Management of Hypertension: The Japanese Society of Hypertension guidelines for the management of hypertension (JSH 2014). Hypertens Res 2014;37:253390.

2 James PA, Oparil S, Carter BL, Cushman WC, Dennison-Himmelfarb C, Handler J, Lackland DT, LeFevre ML, MacKenzie TD, Ogedegbe O, Smith SC Jr, Svetkey LP, Taler SJ, Townsend RR, Wright JT Jr, Narva AS, Ortiz E: 2014 evidence-based guideline for the management of high blood pressure in adults: report from the panel members appointed to the Eighth Joint National Committee (JNC 8). JAMA 2014;311:507-520.

-3 Mancia G, Fagard R, Narkiewicz K, Redón J, Zanchetti A, Bohm M, Christiaens T, Cifkova R, De Backer G, Dominiczak A, Galderisi M, Grobbee DE, Jaarsma T, Kirchhof P, Kjeldsen SE, Laurent S, Manolis AJ, Nilsson PM, Ruilope LM, Schmieder RE, Sirnes PA, Sleight P, Viigimaa M, Waeber B, Zannad F; Task Force Members: 2013 ESH/ESC guidelines for the management of arterial hypertension: the task force for the management of arterial hypertension of the European Society of Hypertension (ESH) and of the European Society of Cardiology (ESC). J Hypertens 2013;31:1281-1357.

-4 Weber MA, Schiffrin EL, White WB, Mann S, Lindholm LH, Kenerson JG, Flack JM, Carter BL, Materson BJ, Ram CV, Cohen DL, Cadet JC, Jean-Charles RR, Taler S, Kountz D, Townsend R, Chalmers J, Ramirez AJ, Bakris GL, Wang J, Schutte AE, Bisognano JD, Touyz RM, Sica D, Harrap SB: Clinical practice guidelines for the management of hypertension in the community. A statement by the American Society of Hypertension and the International Society of Hypertension. J Hypertens 2014;32:3-15.

5 Liu LS; Writing Group of 2010 Chinese Guidelines for the Management of Hypertension: 2010 Chinese guidelines for the management of hypertension (in Chinese). Chin J Cardiol 2011;39:579-615.

6 Wu X, Duan X, Gu D, Hao J, Tao S, Fan D: Prevalence of hypertension and its trends in Chinese populations. Int J Cardiol 1995;52:39-44.

-7 Li LM, Rao KQ, Kong LZ, Yao CH, Xiang HD, Zhai FY, Ma GS, Yang XG; Technical Working Group of China National Nutrition and Health Survey: A description on the Chinese National Nutrition and Health Survey in 2002 (in Chinese). Chin J Epidemiol 2005;26:478-484.

-8 Yang ZJ, Liu J, Ge JP, Chen L, Zhao ZG, Yang WY; China National Diabetes and Metabolic Disorders Study Group: Prevalence of cardiovascular disease risk factor in the Chinese population: the 2007-2008 China National Diabetes and Metabolic Disorders Study. Eur Heart J 2012;33:213-220.

>9 Sheng CS, Liu M, Kang YY, Wei FF, Zhang L, Li GL, Dong Q, Huang QF, Li Y, Wang JG: Prevalence, awareness, treatment and control of hypertension in elderly Chinese. Hypertens Res 2013;36:824-828.

10 Liu LS, Gong LS; Writing Committee for the Chinese Guidelines for the Management of Hypertension: 2005 Chinese guidelines for the management of hypertension (in Chinese). Chin J Hypertens 2005;suppl 134:2-41.

11 European Society of Hypertension-European Society of Cardiology Guidelines Committee: 2003 European Society of Hypertension-European Society of Cardiology guidelines for the management of arterial hypertension. J Hypertens 2003;21:1011-1053.

-12 Chobanian AV, Bakris GL, Black HR, Cushman WC, Green LA, Izzo JL Jr, Jones DW, Materson BJ, Oparil S, Wright JT Jr, Roccella EJ; National Heart, Lung, and Blood Institute Joint National Committee on Prevention, Detection, Evaluation, and Treatment of High Blood Pressure; National High Blood Pressure Education Program Coordinating Committee: The seventh report of the Joint National Committee on Prevention, Detection, Evaluation, and Treatment of High Blood Pressure: the JNC 7 report. JAMA 2003;289:2560-2572.

13 Liu LS; Writing Group of 2010 Chinese Guidelines for the Management of Hypertension: 2010 Chinese guidelines for the management of hypertension (in Chinese). Chin J Hypertens 2011;19:701-742.

14 Liu L, Wang JG, Gong L, Liu G, Staessen JA; Systolic Hypertension in China (Syst-China) Collaborative Group: Comparison of active treatment and placebo for older Chinese patients with isolated systolic hypertension. J Hypertens 1998;16:1823-1829.

15 Wang JG, Staessen JA, Gong L, Liu L; Systolic Hypertension in China (Syst-China) Collaborative Group: Chinese trial on isolated systolic hypertension in the elderly. Arch Intern Med 2000;160:211-220.

-16 Gong L, Zhang W, Zhu Y, Zhu J, Kong D, Pagé V, Ghadirian P, LeLorier J, Hamet P: Shanghai trial of nifedipine in the elderly (STONE). J Hypertens 1996;14:1237-1245.

17 Liu L, Zhang Y, Liu G, Li W, Zhang X, Zanchetti A; FEVER Study Group: The Felodipine Event Reduction (FEVER) Study: a randomized long-term placebo-controlled trial in Chinese hypertensive patients. J Hypertens 2005; 23:2157-2172.

18 Wang JG, Kario K, Lau T, Wei YK, Park CG, Kim CH, Huang J, Zhang WZ, Li Y, Yan P, Hu D: Use of the dihydropyridine calcium channel blockers in the management of hypertension in Eastern Asians: a scientific statement of the Asian Pacific Heart Association. Hypertens Res 2011;34:423-430.

19 Hypertension Council of the Chinese Society of Cardiology: A science advisory on the use of morning blood pressure in the management of hypertension (in Chinese). Chin J Cardiol 2014;42:721-725.

20 Consensus Writing Committee: Chinese expert consensus document on antihypertensive therapy with singlepill combination (in Chinese). Chin J Hypertens 2012;20:624-628. 
21 Hu DY, Liu LS, Yu JM, Yao CH; China STATUS Study Group: National survey of blood pressure control rate in Chinese hypertensive outpatients - China STATUS (in Chinese). Chin J Cardiol 2010;38:230-238.

22 Wang JG, Zeng WF, He YS, Chen LL, Wei M, Li ZP, Zhang BW, Li Y; EXAM Investigators: Valsartan/amlodipine compared with nifedipine GITS in patients with hypertension inadequately controlled by monotherapy. Adv Ther 2013;30:771-783.

23 Huang QF, Sheng CS, Li Y, Ma GS, Dai QY, Wang JG; INCENT Investigators: Efficacy and safety of a fixed combination of irbesartan/hydrochlorothiazide in Chinese patients with moderate and severe hypertension. Drugs R D 2013;13:109-117.

24 Wang JG: Management of hypertension according to stage, severity and pathogenesis of the disease. J Intern Med Conc Pract 2014;9:365-368.

25 Parati G, Stergiou G, O’Brien E, Asmar R, Beilin L, Bilo G, Clement D, de la Sierra A, de Leeuw P, Dolan E, Fagard R, Graves J, Head GA, Imai Y, Kario K, Lurbe E, Mallion JM, Mancia G, Mengden T, Myers M, Ogedegbe G, Ohkubo T, Omboni S, Palatini P, Redon J, Ruilope LM, Shennan A, Staessen JA, vanMontfrans G, Verdecchia P, Waeber B, Wang J, Zanchetti A, Zhang Y; European Society of Hypertension Working Group on Blood Pressure Monitoring and Cardiovascular Variability: European Society of Hypertension practice guidelines for ambulatory blood pressure monitoring. J Hypertens 2014;32:1359-1366.

26 Shin J, Park JB, Kim K, Kim JH, Yang DH, Pyun WB, Kim YG, Kim GH: 2013 Korean Society of Hypertension guidelines for the management of hypertension. Part I - epidemiology and diagnosis of hypertension. Clin Hypertens 2015;21:1. 